\title{
Compression testing of a sintered Ti6Al4V powder compact for biomedical applications
}

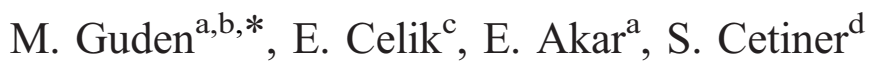 \\ ${ }^{a}$ Department of Mechanical Engineering, Izmir Institute of Technology, Gulbahce Koyu, Urla, Izmir, Turkey \\ ${ }^{\mathrm{b}}$ Center for Materials Research, Izmir Institute of Technology, Gulbahce Koyu, Urla, Izmir, Turkey \\ ${ }^{\mathrm{c}}$ Materials Science and Engineering Program, Izmir Institute of Technology, Gulbahce Koyu, Urla, Izmir, Turkey \\ ${ }^{\mathrm{d}}$ Hipokrat A.Ş., 407/6 Sok., No:10, Pınarbașı, Izmir, Turkey \\ Received 18 June 2004; accepted 3 January 2005
}

\begin{abstract}
In this study, the compression deformation behavior of a Ti6A14V powder compact, prepared by the sintering of cold compacted atomized spherical particles $(100-200 \mu \mathrm{m})$ and containing $36-38 \%$ porosity, was investigated at quasi-static $\left(1.6 \times 10^{-3}-1.6 \times 10^{-1} \mathrm{~s}^{-1}\right)$ and high strain rates $\left(300\right.$ and $\left.900 \mathrm{~s}^{-1}\right)$ using, respectively, conventional mechanical testing and Split Hopkinson Pressure Bar techniques. Microscopic studies of as-received powder and sintered powder compact showed that sintering at high temperature $\left(1200{ }^{\circ} \mathrm{C}\right)$ and subsequent slow rate of cooling in the furnace changed the microstructure of powder from the acicular alpha $(\alpha)$ to the Widmanstätten $(\alpha+\beta)$ microstructure. In compression testing, at both quasi-static and high strain rates, the compact failed via shear bands formed along the diagonal axis, $45^{\circ}$ to the loading direction. Increasing the strain rate was found to increase both the flow stress and compressive strength of the compact but it did not affect the critical strain for shear localization. Microscopic analyses of failed samples and deformed but not failed samples of the compact further showed that fracture occurred in a ductile (dimpled) mode consisting of void initiation and growth in $\alpha$ phase and/or at the $\alpha / \beta$ interface and macrocracking by void coalescence in the interparticle bond region.
\end{abstract}

(C) 2005 Elsevier Inc. All rights reserved.

Keywords: Powder processing; Sintering; Ti alloy; Compression test; Strain rate

* Corresponding author. Department of Mechanical Engineering, Izmir Institute of Technology, Gulbahce Koyu, Urla, Izmir, Turkey. Tel.: +90 232 4986595; fax: +902324986505.

E-mail address: mustafaguden@iyte.edu.tr (M. Guden).

\section{Introduction}

Porous components based on biocompatible metallic materials such as Ti, Ti6Al4V alloy (Ti64) and stainless steel are expected to provide better interaction with bones. This is due to the higher degree of bone growth into porous surfaces and the higher degree of body fluid transport through three-dimen- 
sional interconnected array of pores [1], leading to improved implant fixation. Furthermore, the relatively low elastic moduli of porous metals as compared with those of bulk metals are expected to reduce the extent of stress shielding, which causes the well-known "implant loosening", and hence to prolong implant life-time [2]. By reducing the "elastic-mismatch" as well as the "strength-mismatch" between metallic implant and bone, it is expected to result in better performance of the implant-bone compound, which can be called an "iso-elastic multi-material system". For this purpose numerous innovative investigations have been undertaken world-wide.

Open cell Ti foams and powder compacts, potentially to be used in biomedical applications, were prepared using the space holder [3-5] and the sintering of powder compacts [6] processes, respectively. The space holder method allows a direct near net-shape fabrication of foamed implant components having an elastic modulus comparable to that of natural bone and with a relatively homogeneous pore structure and a high level of porosity $(60-80 \%)$ [3-5]. $\mathrm{Oh}$ and co-workers [6] have recently reported that the modulus and bending strength of sintered Ti powder compacts were also comparable with those of human cancelleous bone. It was further shown by the same authors that the porosity level of sintered Ti compact suitable for bone replacement was around $30 \%$, which was in accord with the proposed optimal porosity for the ingrowths of new-bone tissues. However, the compressive yield strength of sintered Ti compacts was lower than that of the human cortical bone, which was assumed to be due to the relatively low yield strength of Ti powder [6]. One way of increasing the strength and hence producing stronger sintered powder compacts is to use biocompatible stronger $\mathrm{Ti}$ alloy powders, such as Ti64.

In this experimental study, the compressive mechanical behavior of a Ti64 powder compact that can potentially be used in biomedical applications as load carrying implants, including human cortical bone replacement, was investigated at both quasi-static $\left(1.6 \times 10^{-3}-1.6 \times 10^{-1} \mathrm{~s}^{-1}\right)$ and high strain (300 and $900 \mathrm{~s}^{-1}$ ) rates. The work described here focused on (a) compression mechanical properties at quasi-static and high strain rates and (b) the deformation and failure mechanisms under compressive loads. The interest in the strain rate dependent properties of the compact simply arises from the fact that the mechanical properties of natural bone are strain rate sensitive, as shown by Yeni and Fyrie [7] on the basis of an extensive literature survey.

\section{Materials and testing methods}

The sintered powder compact was prepared using atomized spherical particles (Phelly Materials). The chemical composition of the powder complied with ASTM 1580-1 standard [8] as tabulated in Table 1. The particle size ranged between 74 and $250 \mu \mathrm{m}$ with a mean particle size of $140 \mu \mathrm{m}$. The powder was sieved in the particle size range of 100-200 $\mu \mathrm{m}$ with a mean particle size of $\sim 170 \mu \mathrm{m}$. Green powder compacts (length $10 \mathrm{~mm}$, diameter $15 \mathrm{~mm}$ ) were compacted at room temperature inside a tool steel die at a pressure of $400 \mathrm{MPa}$ using a PVA solution $(10 \%$ by volume) as the binding material in the amount of $10 \%$ by weight. The green compacts were sintered at $1200{ }^{\circ} \mathrm{C}$ for $2 \mathrm{~h}$ in a tightly enclosed horizontal tube furnace under an atmosphere of high purity (99.998\%) Ar. The compacts were inserted in the furnace at room temperature inside an enclosed Ti box on a graphite plate that prevented bonding between the Ti box and the compacts. The compacts were heated and cooled with a rate of $5{ }^{\circ} \mathrm{C}$ per minute. In the heating cycle, the compacts were kept at $450{ }^{\circ} \mathrm{C}$ for $0.5 \mathrm{~h}$ in order to allow the complete burning of the binder.

Quasi-static compression tests were conducted on a displacement-controlled SHIMADZU AG-I universal tension-compression test machine with cross-head speeds of 1,10 and $100 \mathrm{~mm}$ per minute, corresponding

Table 1

Chemical composition of Ti64

\begin{tabular}{llllllllllc}
\hline Element & $\mathrm{Al}$ & $\mathrm{V}$ & $\mathrm{O}$ & $\mathrm{Fe}$ & $\mathrm{C}$ & $\mathrm{H}$ & $\mathrm{N}$ & $\mathrm{Cu}$ & $\mathrm{Sn}$ & $\mathrm{Ti}$ \\
\hline ASTM F1580-1 & $5.5-6.75$ & $3.5-4.5$ & 0.2 & 0.3 & 0.08 & 0.015 & 0.05 & 0.1 & 0.1 & $\mathrm{Bal}$ \\
Powder & 6.38 & 3.93 & 0.17 & 0.27 & 0.013 & 0.003 & 0.0072 & 0.091 & $<0.01$ & $\mathrm{Bal}$ \\
\hline
\end{tabular}


to strain rates of $1.6 \times 10^{-3}, 1.6 \times 10^{-2}$ and $1.6 \times 10^{-1}$ $\mathrm{s}^{-1}$, respectively. High strain rate compression tests were performed using a compression type Split Hopkinson Pressure Bar (SHPB) set-up at 300 and $900 \mathrm{~s}^{-1}$. The SHPB technique of testing of materials at moderate strain rates $\left(1000\right.$ 's s $\left.{ }^{-1}\right)$ is a widely accepted and used method for dynamical studies. In this method, a small cylindrical specimen of the material to be tested is sandwiched between two long bars, the incident and transmitter bars (see Fig. 1(a)). By impacting the incident bar with a third bar (the striker bar), a constant amplitude elastic compressive wave is created and then propagates down the incident bar to the specimen/bar interfaces. When this elastic wave reaches the bar-specimen interfaces, part of it is reflected back to the incident bar and the rest is transmitted through the transmitter bar, depending on the relative difference between the acoustic impedance of the bar material and the specimen. By measuring the corresponding pulses on the incident and transmitter bars with strain gages mounted on them, the specimen response (stress-strain) to the applied compressive load can be easily established using uniaxial elastic wave theory. The SHPB apparatus used consists of 19 $\mathrm{mm}$ diameter bars of Inconel 718. The striker bar is $326 \mathrm{~mm}$ long, the incident bar $3450 \mathrm{~mm}$ and the transmitter bar $1850 \mathrm{~mm}$. More detailed information on the SHPB is given elsewhere [9]. The strain rate $(\dot{\varepsilon})$, the strain $(\varepsilon)$ and the stress $(\sigma)$ of the tested sample were calculated using the following equations:

$$
\begin{aligned}
& \dot{\varepsilon}(t)=-\frac{2 C_{\mathrm{b}}}{L_{\mathrm{s}}} \varepsilon_{\mathrm{r}}(t) \\
& \varepsilon(t)=-\frac{2 C_{\mathrm{b}}}{L_{\mathrm{s}}} \int_{0}^{t} \varepsilon_{\mathrm{r}}(t) \mathrm{d} t \\
& \sigma(t)=\frac{E_{\mathrm{b}} A_{b}}{A_{\mathrm{s}}} \varepsilon_{\mathrm{t}}(t)
\end{aligned}
$$

where $C_{\mathrm{b}}$ is the elastic wave velocity in the bar, $E_{\mathrm{b}}$ is the elastic modulus of the bar, $L_{\mathrm{s}}$ is the sample length and $A_{\mathrm{s}}$ and $A_{\mathrm{b}}$ are, respectively, the sample and the bar cross-sectional areas. $\varepsilon_{\mathrm{I}}, \varepsilon_{\mathrm{r}}$ and $\varepsilon_{\mathrm{t}}$ are, respectively, the incident, reflected and transmitted strains measured from strain gages on the bar. A typical SHPB test record of a tested sample of compact, composing of incident, reflected and transmitted strain records, is shown in Fig. 1(b). Since the transmitter bar of the SHPB is shorter than the incident bar, the tensile wave reflected from the transmitter bar end separates the bars and, therefore, the sample deforms only once under compression. The specimen dimensions, $15 \mathrm{~mm}$ in diameter and $10 \mathrm{~mm}$ in height, were the same for both quasi-static and high strain rate tests. At least three compression tests were performed at each strain

(a)

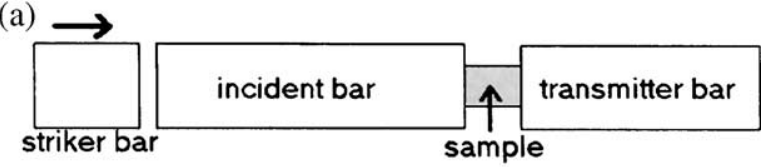

(b)

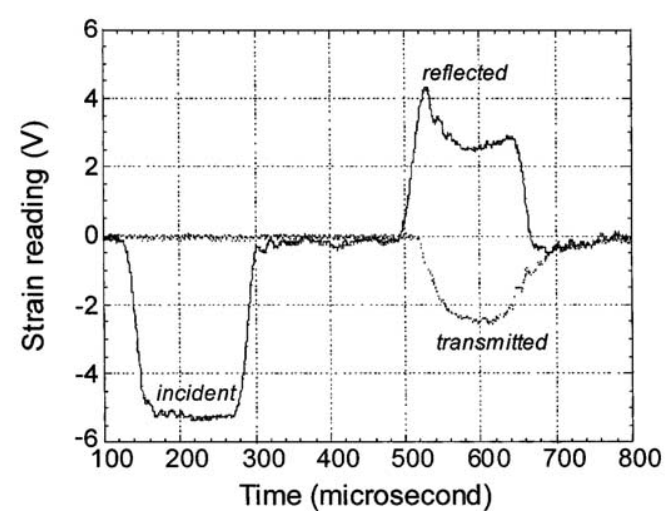

Fig. 1. (a) Schematic of SHPB and (b) typical SHPB strain gage readings of Ti64 compact. 
rate studied. A few samples were also recovered before failure at quasi-static and high strain rates in order to assess the deformation modes of particles.

Microscopic analysis was performed on the vacuum epoxy-mounted as-received powder and untested and compression tested compact samples using light optical microscopy and a Philips XL30-SFEG scanning electron microscope (SEM) with an Energy Dispersive X-ray (EDX) analyzer. Polished sample cross-sections were etched with Kroll's reagent ( $3 \mathrm{ml}$ $\mathrm{HF}, 6 \mathrm{ml} \mathrm{HNO}_{3}$ in $100 \mathrm{ml} \mathrm{H} \mathrm{H}_{2} \mathrm{O}$ ). The percent porosity of the sintered compact was measured by the Archimedes' method after coating the compact surfaces with paraffin, similar to the method used in [10]. The open and closed porosities of compacts were calculated by the differences between dry and wet weights (boiling in water). Finally, the average pore size and the percentages and thicknesses of $\alpha$ and $\beta$ phases were determined using an image analyzer.

\section{Results}

The porosity of the compact was determined to be $37 \pm 1 \%$ (average of 10 sample measurements). The compact was also determined to contain $100 \%$ threedimensional interconnected pores ranging in size between 16 and $200 \mu \mathrm{m}$ with a mean pore size of $63 \mu \mathrm{m}$, calculated using the liner intercept method on the light optical micrographs of the polished surfaces.

The SEM image of the as-received spherical powders and the light optical microscope image of the etched cross-section of a particle are shown in Fig. 2(a) and (b), respectively. The as-received particles were spherical and had nearly uniform particle size as shown in Fig. 2(a). The microstructure of the asreceived powder shown in Fig. 2(b) was composed of needle-like $\alpha$-phase, referred as acicular alpha $(\alpha)$ [11]. Sintering at high temperature above the beta $(\beta)$ transition temperature $\left(1050{ }^{\circ} \mathrm{C}\right)$ and subsequent slow rate cooling in the furnace under $\mathrm{Ar}$ atmosphere however resulted in the development of the so-called Widmanstätten microstructure (Fig. 3(a)). In this structure, colonies of $\beta$ lathes (bcc and rich in V) and $\alpha$ platelets (hcp and rich in $\mathrm{Al}$ ) formed inside the prior $\beta$ grains (Fig. 3(b)). The percentage and thickness of $\beta$ phase were found to be $18-20 \%$ and $0.2-1$ $\mu \mathrm{m}$, respectively. The thickness of $\alpha$ platelets varied (a)

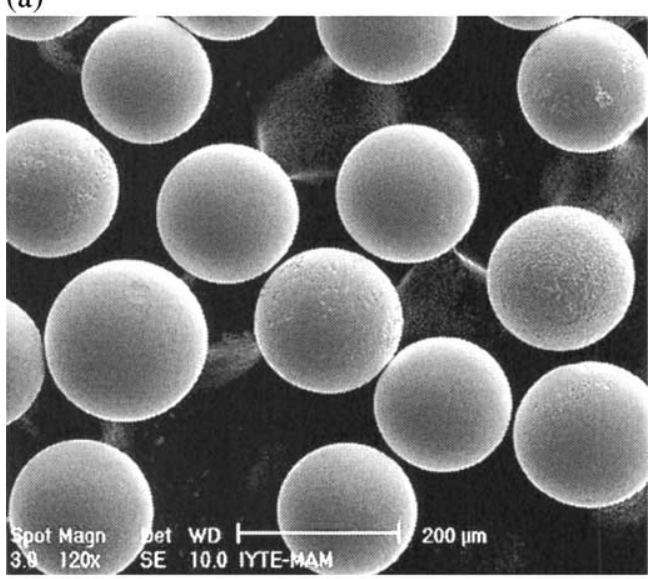

(b)

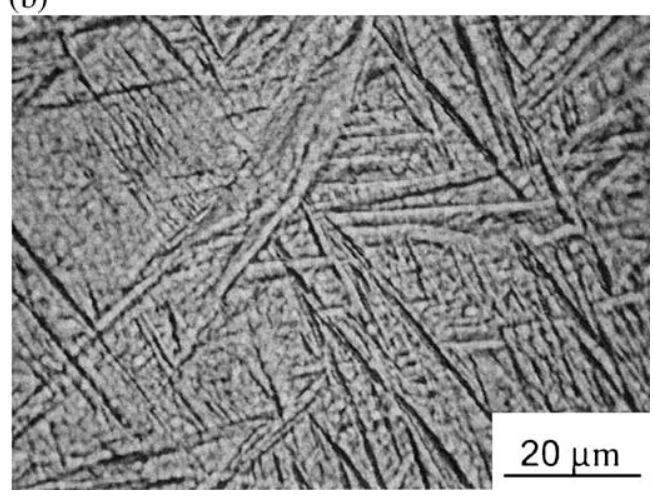

Fig. 2. (a) SEM image of as-received powder and (b) light optical micrograph showing fine needle-like $\alpha$-phase (acicular alpha) microstructure of the powder.

between 4 and $8 \mu \mathrm{m}$ and it was also microscopically observed that the thickness of the $\alpha$ platelets increased at and near the interparticle bond region.

A typical compression stress-strain curve of the compact at a quasi-static strain rate $\left(1.6 \times 10^{-3} \mathrm{~s}^{-1}\right)$ is shown in Fig. 4 and can be considered in three distinct deformation regions marked as I, II and III. In region I, the compact is elastically compressed up to about the proportional limit. In region II, particle inelastic deformation takes place under normal and shear forces as will be elaborated later. At and/or before maximum stresses or compressive strength, marked with arrows in Fig. 4, deformation presumably starts to become non-uniform as two conic shear bands begin to develop along the diagonal axes of the compact, at $45^{\circ}$ to the loading direction (Fig. 5(a)). Deformation localization in the shear bands or shear 
(a)

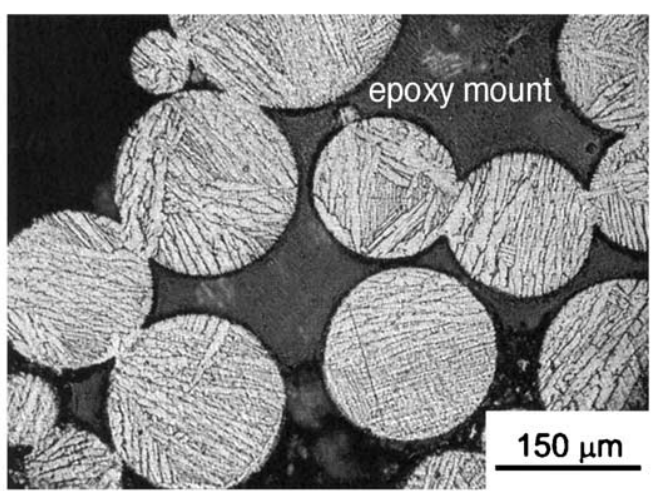

(b)

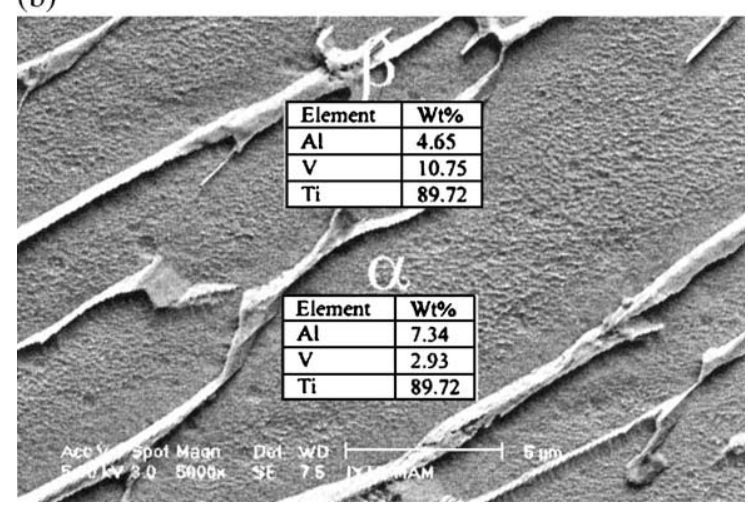

Fig. 3. (a) Light optical micrograph showing interparticle bonding and Widmanstätten microstructure of sintered compact and (b) magnified (SEM) image of Widmanstätten microstructure showing $\alpha$ and $\beta$.

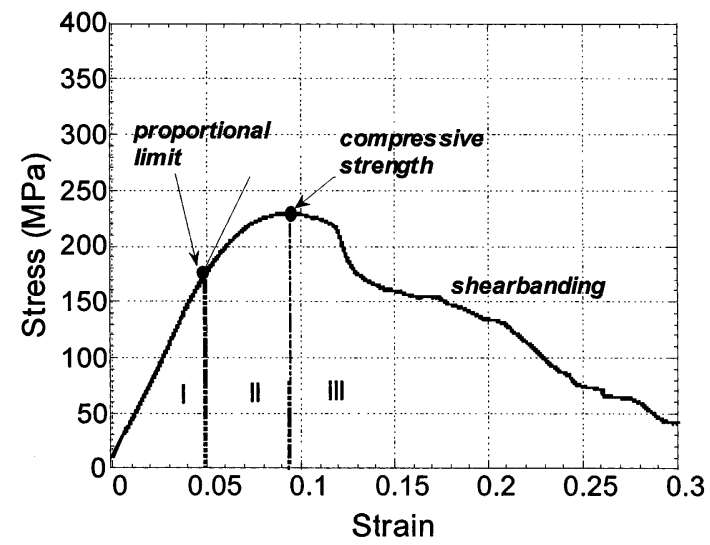

Fig. 4. Typical compression stress-strain curve of Ti64 compact at quasi-static strain rates $\left(1.6 \times 10^{-3} \mathrm{~s}^{-1}\right)$, showing 3 different deformation regions. (a)

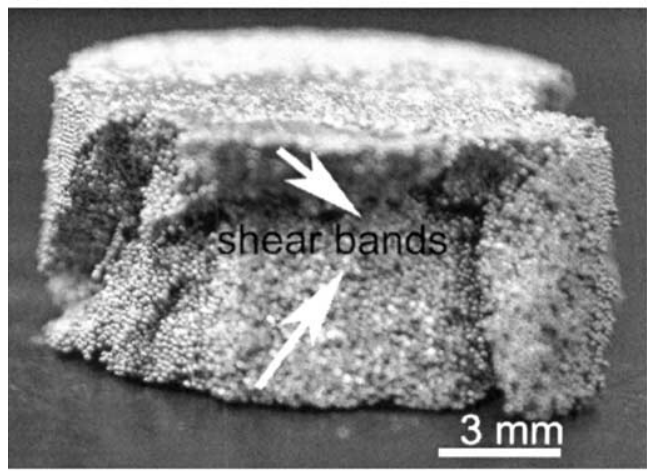

(b)

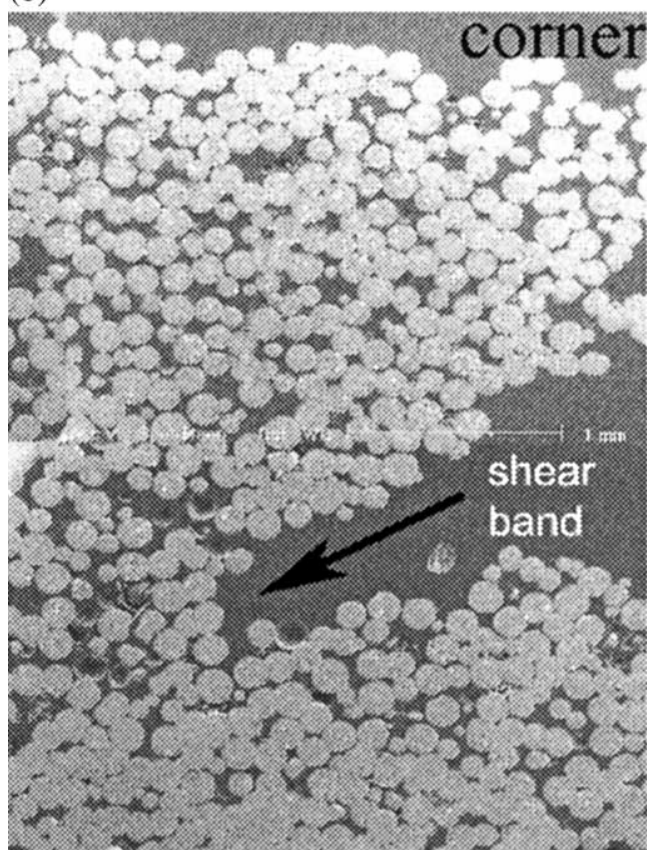

Fig. 5. (a) Shear bands in a failed compact sample tested at $1.6 \times 10^{-3} \mathrm{~s}^{-1}$ and (b) the montage of SEM images of compact sample tested at $300 \mathrm{~s}^{-1}$, showing shear band progression starting from the corner, in Region III of Fig. 4.

banding results in a reduction in the load carrying capacity of the deforming compact in Region III (Fig. 4). Complete failure occurs with the separation of the bonded particles on the shear bands, starting from the corners of the cylindrical compact sample (Fig. 5(a) and (b)). This failure mode of deformation was found to be the same at both quasi-static and high strain rates. Increasing the strain rate, however, increases the flow stress and the compressive strength of the 
compact. The compressive strength increases from about $240 \mathrm{MPa}$ at quasi-static rates $\left(1.6 \times 10^{-3} \mathrm{~s}^{-1}\right)$ to $300 \mathrm{MPa}$ at high strain rates $\left(900 \mathrm{~s}^{-1}\right)$ without significantly affecting the strain corresponding to the maximum compressive stress (Fig. 6).

Compared with the $\mathrm{Ti}$ compacts that were previously investigated by $\mathrm{Oh}$ and coworkers [6], the Ti64 powder compact provided higher yield strength at similar porosity levels and quasi-static strain rates. For example, the $0.2 \%$ proof strength of the $\mathrm{Ti}$ compact with a porosity level around $30 \%$ was reported nearly $60 \mathrm{MPa}$ [6], while the prepared compact showed proportional limits higher than 150 MPa (Fig. 4). The yield strength of the compact was also found to be comparable to that of human cortical bone, 104-125 MPa measured within the strain rate regime of $2-5 \times 10^{-2} \mathrm{~s}^{-1}$ [12]. Hence the compact material also satisfies the strength requirement for cortical bone replacement.

The polished and etched cross-sections of samples deformed until about the maximum stress in Region II of Fig. 4 showed that particles were compressed into oblate spheroids and complex shapes, particularly near the shear band region (Fig. 7(a)). SEM micrographs of the fracture surface of a failed specimen shown in Fig. 7(b) and (c) feature few of the important deformation mechanisms of compact as (i) the separation of particles primarily occurred at the interparticle bond region, (ii) the fracture of interparticle bond region was of the ductile type and composed of dimples, (iii) originally non-contacting particles developed contacts with neighboring par-

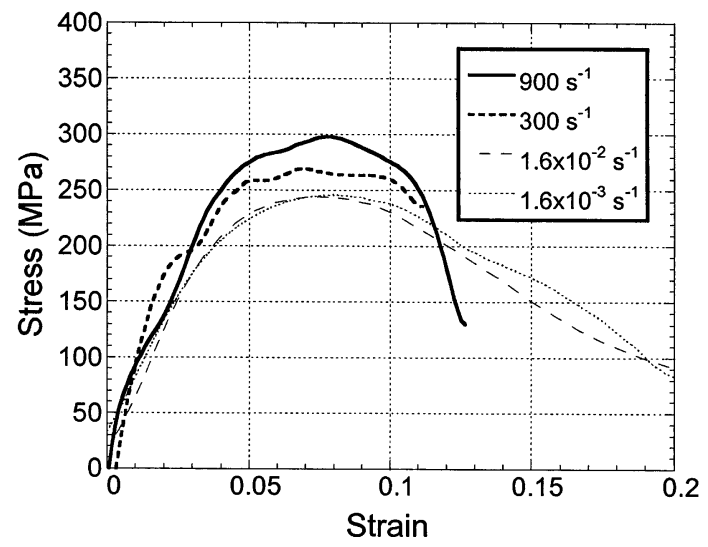

Fig. 6. Compression nominal stress-strain curves of compact at various strain rates. (a)

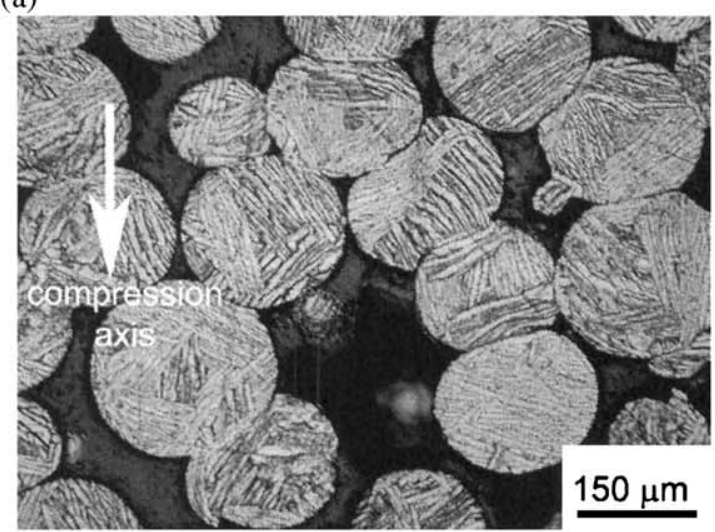

(b)

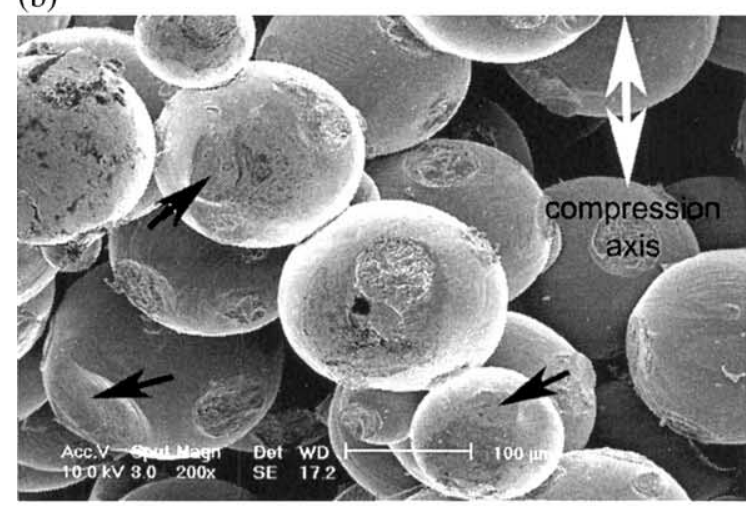

(c)

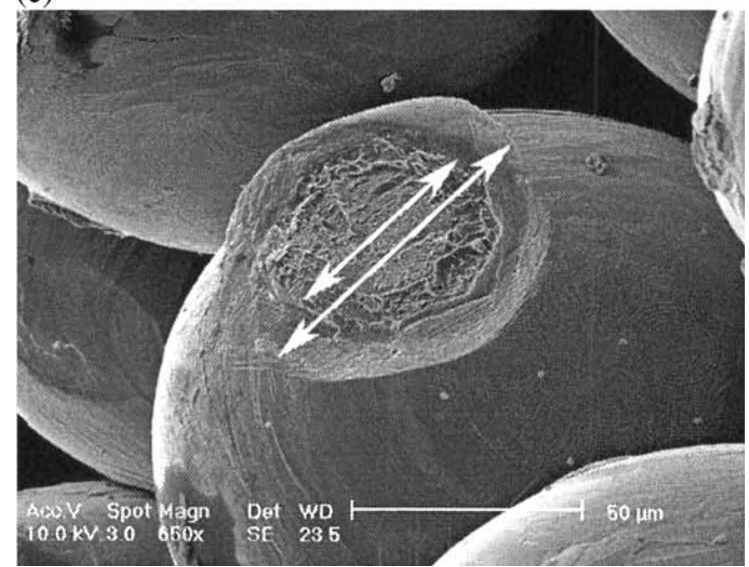

Fig. 7. SEM images of tested compact sample $\left(1.6 \times 10^{-3} \mathrm{~s}^{-1}\right)$ showing (a) complex deformation of particles in contact near to shear band, (b) separated particles on the shear band and (c) interparticle bond area and contact region on a separated particle.

ticles during deformation as marked by arrows in Fig. 7(b), and (iv) as a result of particle inelastic deformation the contact area between bonded particles 
increased over the interparticle bond area (Fig. 7(c)). The presence of localized shear regions on the interparticle bond regions (Fig. 8(a) and (b)) and the evidence of ductile dimpled fracture surfaces (Fig. 9) further indicated the development of large shear and/ or normal stresses between particles in the interparticle bond regions. In samples deformed through Region III, voids and macrocracks were observed in the interparticle bond region at both quasi-static and high strain rates (Fig. 10(a)). Voids were observed to initiate primarily in $\alpha$ platelets and/or at the $\beta / \alpha$ interface, and their sizes before coalescence were determined to be $1-2 \mu \mathrm{m}$. The growth and coalescence of these voids eventually led to the development of macrocracks and complete separation of the interparticle bond region. Fig. 10(b) shows the magnified SEM image of the interior and tip of a macrocrack. On the crack surface many dimples are seen and the distance between the dimples is in good agreement with the measured void size. Finally, the fracture surface of particles should be composed of

(a)

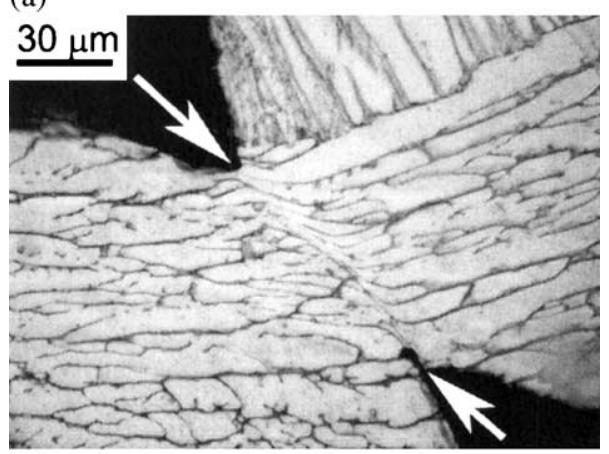

(b)

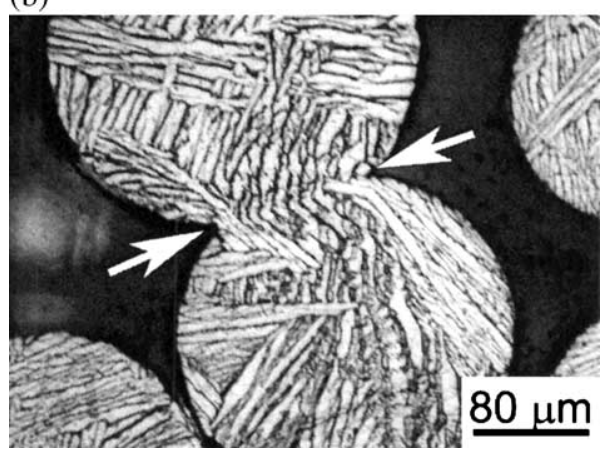

Fig. 8. Development of localized shear regions in interparticle bond regions of compact samples tested (a) $1.6 \times 10^{-3} \mathrm{~s}^{-1}$ and (b) $900 \mathrm{~s}^{-1}$.

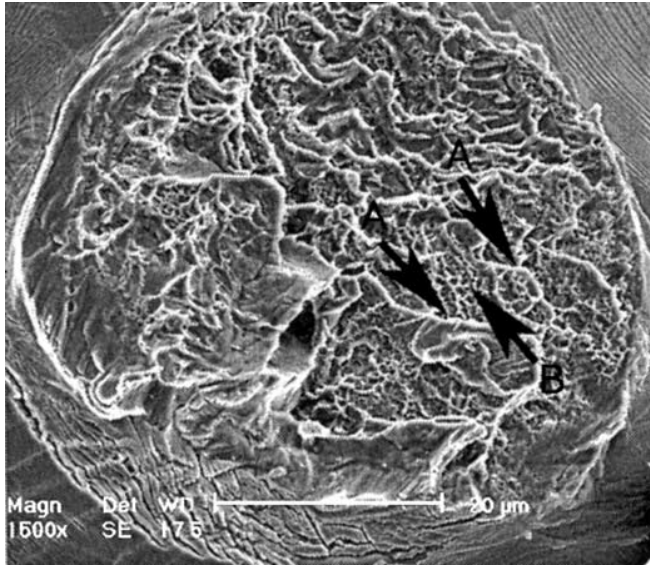

Fig. 9. Dimpled mode of failure of interparticle bond region (sample tested at $1.6 \times 10^{-3} \mathrm{~s}^{-1}$ ).

two different sizes of dimples: small dimples formed by the void coalescence in $\alpha$ platelets with a distance between them determined by the void size $(1-2 \mu \mathrm{m})$ and large dimples formed due to the ductile failure of

(a)

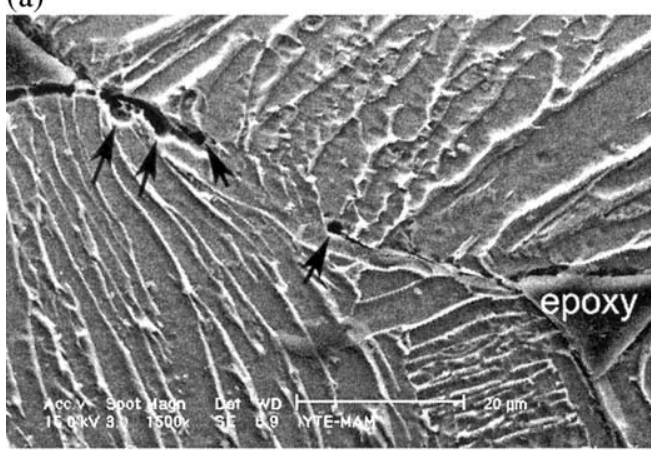

(b)

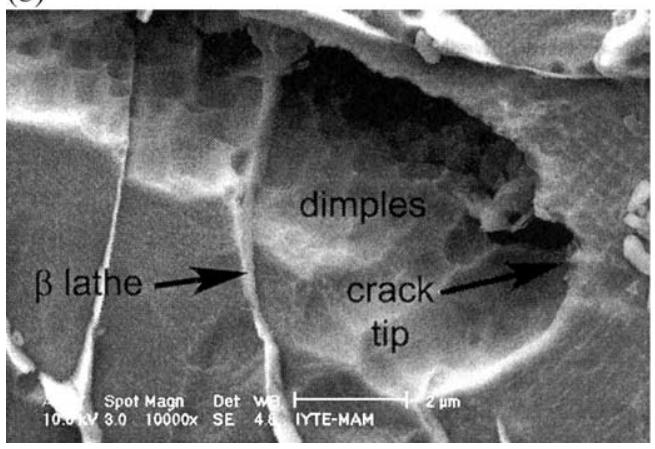

Fig. 10. (a) Voids and macrocracks and (b) interior and crack tip of a macrocrack in interparticle bond region (sample tested at $\left.1.6 \times 10^{-3} \mathrm{~s}^{-1}\right)$ 
$\beta$ lathes with a distance between them determined by the thickness of $\alpha$ phase $(4-8 \mu \mathrm{m})$. These are consistent with the dimples sizes on the fracture surface shown in Fig. 9, composed of large (arrows A) and small (arrow B) dimples with distances comparable with thickness of $\alpha$ platelets and void size. Void initiation and growth and void coalescence leading to ductile dimple type of failure have been commonly observed in bulk Ti64 alloys tested under shear and compression at quasi-static and dynamic strain rates [13-17].

\section{Discussion}

The mean pore size of the prepared compact for cortical bone replacement is smaller than the optimum pore size range required for the attachment and proliferation of new bone tissue and the transport of body fluids $(200$ and $500 \mu \mathrm{m})$ [18]. Alternative ways of increasing the mean pore size without significantly increasing the porosity may include increasing particle size and the addition of predetermined amount and particle size of space holder material such as ammonium bicarbonate [3-5]. The interrelationships between porosity and pore size and the effects of compaction pressure and the addition of space holder should be further investigated in detail for the manufacturing of implant structures with optimum pore size and porosity. However, this is beyond the scope of the present study.

As would be expected, the yield $(\sim 175 \mathrm{MPa})$ and compression strength $(\sim 250 \mathrm{MPa})$ values of the present compact (in which the porosity levels are $36-38 \%$ ) are significantly lower than those of the Widmanstätten-structured bulk alloy tested at quasistatic strain rates ( $\sim 900 \mathrm{MPa}$ yield strength and $\sim 1600$ MPa compression strength [16]). Normalization with this yield strength of bulk alloy gives a normalized compact yield strength value of nearly 0.2 . This value of normalized yield strength also shows a good correlation with the values of normalized flow stresses of a porous iron, shown to be 0.4 and 0.3 for 20 and $30 \%$ porosities, respectively [19].

The strain rate dependent mechanical properties of bulk Ti64 alloy have been subjected to several studies [13-17]. Generally, as the strain rate increased, both the yield and the flow stress values were found to increase. It was also shown that the strain rate sensitivities of Widmanstätten and equiaxed microstructures under compression were similar [14]. Silva and Ramesh [16] reported that the percentage increase in flow stress of a bulk Ti64 alloy from quasistatic $\left(10^{-4} \mathrm{~s}^{-1}\right)$ to high strain rates $\left(\sim 1000 \mathrm{~s}^{-1}\right)$ was $30 \%$. In sintered compacts of Widmanstätten microstructures, a similar effect of increasing strain rate on the flow stress (at 5\% strain) and compressive strength is also seen in Fig. 11; the flow and compressive strength increase with increasing strain rate from quasi-static through the high strain rate regime. It is noted that, between the lowest and highest strain rates, the percentage increase in flow stress, about $27 \%$, is very similar to the reported increase in bulk Ti64 alloy (30\%). The similarity of the strain rate dependencies of the powder compact and bulk Ti64 alloy is also in accord with the previous studies on the rate sensitivities of bulk and porous Ti64 [16] and iron alloys [19], and leads to the conclusion that the powder compact strain rate dependency is merely derived from the rate dependency of bulk Ti64 alloy.

The critical strain, the strain corresponding to the maximum stress and at which shear banding presumably started to develop in the compact, ranged between $7 \%$ and $8 \%$ (Fig. 6), similar to the critical strains $(8-10 \%)$ for strain localization in a bulk Ti64 alloy tested under compression [16]. It is also interesting to note that the strain rate independent critical strain found in the compact within the studied strain rate regime is in good agreement with the study of Silva and Ramesh [16], who showed that shear localization in a bulk Ti64 alloy occurred nearly at the same strain at quasi-static and high strain rates. It was also shown by the same authors that the critical strain level was quite different in the Widmanstätten and equiaxed microstructures of a bulk Ti64 alloy: although the Widmanstätten microstructure showed strain localization at $8-10 \%$ strains, the equiaxed structure did not show any localized shearing [16], confirming a strong dependency of mechanical properties on the microstructure.

The present study has shown that a sintered Ti64 compact with a porosity level of $36-38 \%$ satisfies the strength requirement for the cortical bone replacement. The increase in flow stress and compressive strength of compact with increasing strain rate without any significant reduction in critical 


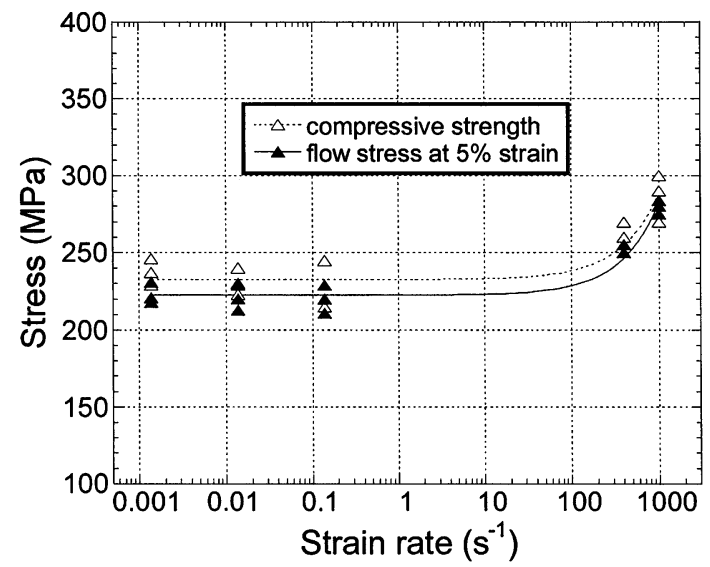

Fig. 11. Compressive stress vs. log strain rate.

strain for localization is certainly beneficial in order to manage sudden increases in the loading rates during service. One of the limitations towards the use of powder compact implants is the relatively low critical strains for shear localization, which could be further optimized with the control of microstructure development and microstructural parameters, including percentages and thicknesses of $\alpha$ and $\beta$ phases through the heat treatment processes applied to bulk Ti64 alloy. Future investigations will therefore be focused on this issue: development of relationships between microstructure and mechanical properties for mechanical property optimization of powder compact.

\section{Conclusions}

The quasi-static and high strain rate compression behavior of a sintered Ti64 alloy compact with 36$38 \%$ interconnected porosity has been investigated. Microstructural analysis of as-received powder and untested and tested sintered compact samples were performed in order to determine microstructure development after sintering and deformation and the failure mechanisms under compressive loading. The following conclusions have been reached:

1. Sintering at high temperature $\left(1200{ }^{\circ} \mathrm{C}\right)$ and subsequent slow (in-furnace) cooling resulted in the powder changing from an acicular $\alpha$ microstructure to a Widmanstätten microstructure.
2. In compression testing, at both quasi-static and high strain rates, the compact failed via shear bands formed along diagonal axis, 45 to the loading direction.

3. Increasing the strain rate was found to increase both the flow stress and the compressive strength of the compact but did not affect the critical strain for shear localization.

4. Microscopic analyses of failed samples and deformed but not failed samples of the compact have shown that fracture occurred in a ductile (dimpled) mode consisting of void initiation and growth in the $\alpha$ phase and/or at the $\alpha / \beta$ interface, and macrocracking by void coalescence in the interparticle bond region.

\section{Acknowledgements}

The authors would like to thank the Technology Development Foundation of Turkey (TTGV) for the grant \#TTGV-102/T13.

\section{References}

[1] Pillar RM. Porous-surfaced metallic implants for orthopaedic applications. J Biomed Mater Res 1987;21:1-3.

[2] Long M, Rack HJ. Titanium alloys in total joint replacement-a materials science perspective. Biomaterials 1998;19:1621-39.

[3] Bram M, Stiller C, Buchkremer HP, Stöver D, Baur H. High purity titanium, stainless steel and superalloy parts. Adv Eng Mater 2000;2:196-9.

[4] Wen CE, Mabuchi M, Yamada Y, Shimojima K, Chino Y, Asahina T. Processing of biocompatible porous Ti and Mg. Scr Mater 2001;45:1147-53.

[5] Wen CE, Yamada Y, Shimojima K, Chino Y, Asahina T, Mabuchi M. Processing and mechanical properties of autogenous titanium implant materials. J Mater Sci 2001; 13:397-401.

[6] Oh IH, Nomura N, Masahashi N, Hanada S. Mechanical properties of porous compacts prepared by powder sintering. Scr Mater 2003;49:1197-202.

[7] Yeni YN, Fyrie DP. A rate-dependent microcrack-bridging model that can explain the strain rate dependency of cortical bone apparent yield strength. J Biomech 2003;36:1343-53.

[8] Standard specification for titanium and Ti6A14V alloy powders for coating surgical implants. ASTM F 1580-95. Philadelphia, PA: American Society for Testing and Materials; 1995.

[9] Güden M, Hall IW. High strain-rate compression testing of a short-fiber reinforced aluminum composite. Mater Sci Eng 1997;A232:1-10. 
[10] Oh IH, Nomura N, Masahashi N, Hanada S. Microstructures and mechanical properties of porous titanium compacts prepared by powder sintering. JIM Mater Trans 2002;43: $443-6$.

[11] Rhodes CG. Microscopy and titanium alloy development. In: Vander Voort GF, editor. Applied metallurgy. New York, NY: Van Nostrand Reinhold Company. 1986. p. 237-49.

[12] Burstein AH, Reilly DT, Martens M. Aging of bone tissue: mechanical properties. J Bone Joint Surg 1976;58A:82-6.

[13] Lee DG, Lee S, Lee CS. Quasi-static and dynamic deformation behaviour of Ti-6Al-4V alloy containing $\alpha_{2}-\mathrm{Ti}_{3} \mathrm{Al}$ precipitates. Mater Sci Eng 2004;A366:25-37.

[14] Johnson AJW, Bull CW, Kumar KS, Briant CL. The influence of microstructure and strain rate on the compressive deformation behaviour of Ti-6Al-4V. Metall Mater Trans 2003; 34A:295-306.
[15] Lee DG, Kim S, Lee S, Lee CS. Effects of microstructural morphology on quasi-static and dynamic deformation behavior of Ti-6Al-4V alloy. Metall Mater Trans 2001;32A:315-24.

[16] Silva MG, Ramesh KT. The rate-dependent deformation and localization of fully dense and porous Ti-6Al-4V. Mater Sci Eng 1997;A232:11-22.

[17] Nasser NS, Guo WG, Nesterenko VF, Indrakanti SS, Gu YB. Dynamic response of conventional and hot isostatically pressed Ti-6Al-4V alloys: experiments and modelling. Mech Mater 2001;22:425-39.

[18] Clemow AJT, Weinstein AM, Klawitter JJ, Koeneman J, Anderson J. Interface mechanics of porous titanium implants. J Biomed Mater Res 1981;15:73-82.

[19] Silva MG, Ramesh KT. The rate dependent deformations of porous pure iron. Int J Plast 1997;13:587-610. 